\title{
Displaying Values, Scripting Stories: Writing Narratives of Environment Citizenship through Permanent Educational Exhibits at Local Nature Preserves
}

\author{
Rebecca Johns, Rachelle Pontes
}

'Exhibit, that's to disturb harmony. Exhibit, that's to trouble the visitor in his intellectual comfort. Exhibit, that's to arouse emotions, anger, desire to know more' (Arnold 2006: 257).

\section{Introduction}

Many city, county, state and national parks and preserves in the United States have educational displays, which typically showcase collections of objects from within the park's boundaries, e.g. bones, shells, rocks, skeletons, feathers, pelts, cones, taxidermy displays, etc., as well as exhibits presenting ecosystems and living elements of the environment. Park exhibits construct a narrative about nature and the human relationship to the environment. The displays and interpretative material speak to visitors of specific environmental values, suggest behaviours toward nature, and tell stories about the history, components and processes of local ecosystems.

Designing educational exhibits at preserves and parks that work on behalf of nature and humans to promote conservation behaviour and sustainable action, and to solve environmental problems, can support the goals of environmental education. However, park exhibits have thus far gone largely unnoticed in the rich debates about museums, science centres, and climate change, and in environmental education (EE) more generally. Given the persistence of multiscale environmental challenges, deepening our understanding of the contribution of preserve exhibits to increasing environmental literacy and public activism is an important goal. Environmental exhibits, however, are neither universal nor benign; they always represent a particular paradigm of human-environment relations. They are influenced by dominant cultural ideologies about human-nature relationships, institutional mission, curatorial knowledge and vision, and the material limitations of each site. Permanent exhibits contain a 'hidden curriculum', which may not be obvious but can be inferred by viewers (Pedersen 2002). As carriers of cultural constructs about human dominion over, responsibility for, and engagement with non-human nature, park displays play a critical role in citizens' perceptions of their responsibility for the environment, and hence, cannot go unexamined. Bringing together analytical tools developed for museum experiences with evaluative frameworks from the field of EE provides a robust set of concepts for understanding the work that exhibits at preserves may do to increase ecoliteracy and public commitment to the environment at local scale.

Discussions about the need to re-examine museums in the context of a 'turbulent and complex world' (Cameron 2015a: 26) reveal the tendency for museum exhibits to serve as hegemonic devices that reproduce hierarchal models of knowledge acquisition and transmission. New scholarship on museums and heritage interpretation argues for a re-scripting of exhibits toward a polyphonic, participatory, and emancipatory process of knowledge creation (Janes 2007; Cameron 2015b). In relation to environmental crises in particular, museums may be 'conflict adverse' (Cameron et al. 2015: 252) and reinforce science as authority, silencing alternative ways of experiencing environmental change. Perhaps even more relevant for our purposes here are critiques of the manner in which natural history museums reinforce patriarchal and dominionistic human-nature relationships. As Cameron and colleagues demonstrate in their work on the London Museum of Science, exhibits often work to reinforce human superiority over non-human nature, positioning humans as custodians of a fallen and passive world, or worse, as commanders looking down on a world to be manipulated and

Museum \& Society, November 2020. 18(4) 386-408 @ 2020, Rebecca Johns, Rachelle Pontes. ISSN 1479-8360 
controlled through scientific-techno regimes (Cameron et al. 2015). Museums have made some progress, though, toward fully engaging with the politics and complex socio-economic processes that perpetuate environmental harm such as climate change, but may replicate a common error by targeting an audience narrowly imagined as citizen-consumers in need of policing. Educational exhibits at local parks do not operate on the massive scale of national institutions such as the Smithsonian or the London Museum of Science. Previous research indicates that local park curators have only just begun to incorporate humans as agents of environmental change in their programming (Johns and Pontes 2019). On the other hand, recognition that environmental challenges are experienced variably by diverse populations in geographically specific environments and that museums should, therefore, emphasize local context provides smaller parks with an advantage. Educational displays at city and county parks are designed specifically to represent local environments; hence, they are well-positioned to incorporate local needs and actions regarding environmental concerns. As Salazar notes (2011: 125), 'museums closely affiliated with local communities may have a significant role to play as they become closely engaged in contexts where adaptation, mitigation and action on climate change actually takes place'. Local parks may be key elements in the first line of defence of the environment and the starting point for the creation of environmental citizens.

In this paper, we analyze educational exhibits at three popular nature preserves in Pinellas County, Florida. Drawing from EE's emphasis on the development of citizens who will act on behalf of nature and are attentive to patterns of inclusion and exclusion, we ask who these citizens are imagined to be, and what they are expected to do. Exhibition storylines may have a powerful impact on how visitors see themselves in relation to nature, and may reproduce or destabilize hegemonic tropes of human control and dominance over nature. This interdisciplinary analysis, therefore, allows a rigorous inquiry into the way that nature preserves' exhibits function to engage visitors in meaningful discourse about human-nature relationships.

Accordingly, using a rhetorical analysis of artefacts and textual and visual interpretation in permanent exhibits at three nature preserves, this paper addresses the following research questions:

1. How are opportunities created to enhance visitors' knowledge and understanding, to engage them emotionally, and to motivate sustainable action?

2. What role is imagined for humans in the narrative about the local environment and human-nature relationships? Are dominant values of human exceptionalism and dualistic constructs of human separation from nature reproduced in the exhibits, or challenged by them?

3. Who is the environmental citizen constructed by the exhibits? What are these imagined citizens asked to do on behalf of the larger community?

To address these questions, we draw on concepts of emotional engagement, co-creation of narratives through inquiry and dialogue, and the move to position museums as socially engaged and democratic institutions that promote planetary well-being. We search for the ideological messages about humans and nature that are embedded in exhibit design, and we listen for silences and exclusions in narratives of citizenship and action.

\section{Study Sites}

Three popular nature preserves from Pinellas County, Florida were chosen as study sites (Figure 1). Florida faces serious environmental challenges, not the least of which is the threat of climate change. Pinellas County is the most densely populated and developed county in the state; thus, the role of preserves in local citizen education is critical. Urgent action is needed to protect unique ecosystems and species, while also developing climate resiliency for vulnerable human populations. The three preserves together represent the expanse of the county peninsula from north to south and east; include common ecosystem types; and exemplify both city- and county-managed natural spaces. All three preserves contain material educational exhibits. 
Pinellas County Case Study Nature Preserves

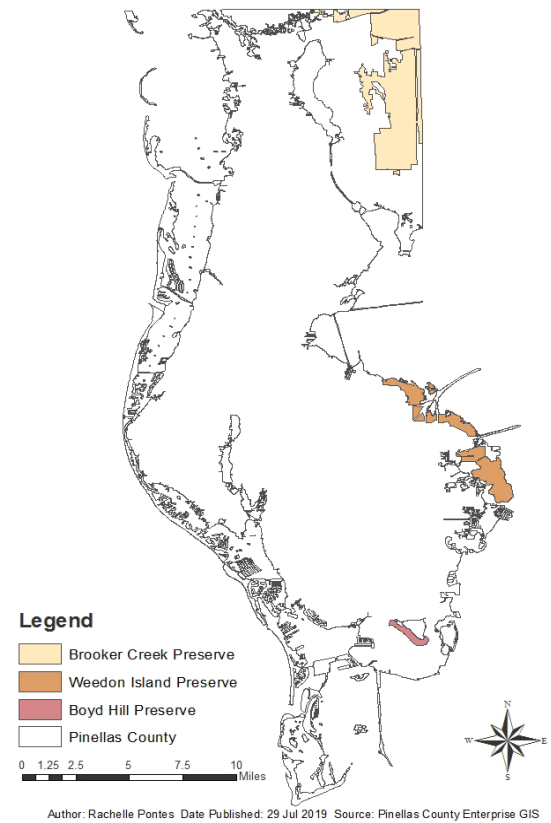

Figure 1: Study Site Map animal parts or taxidermy.

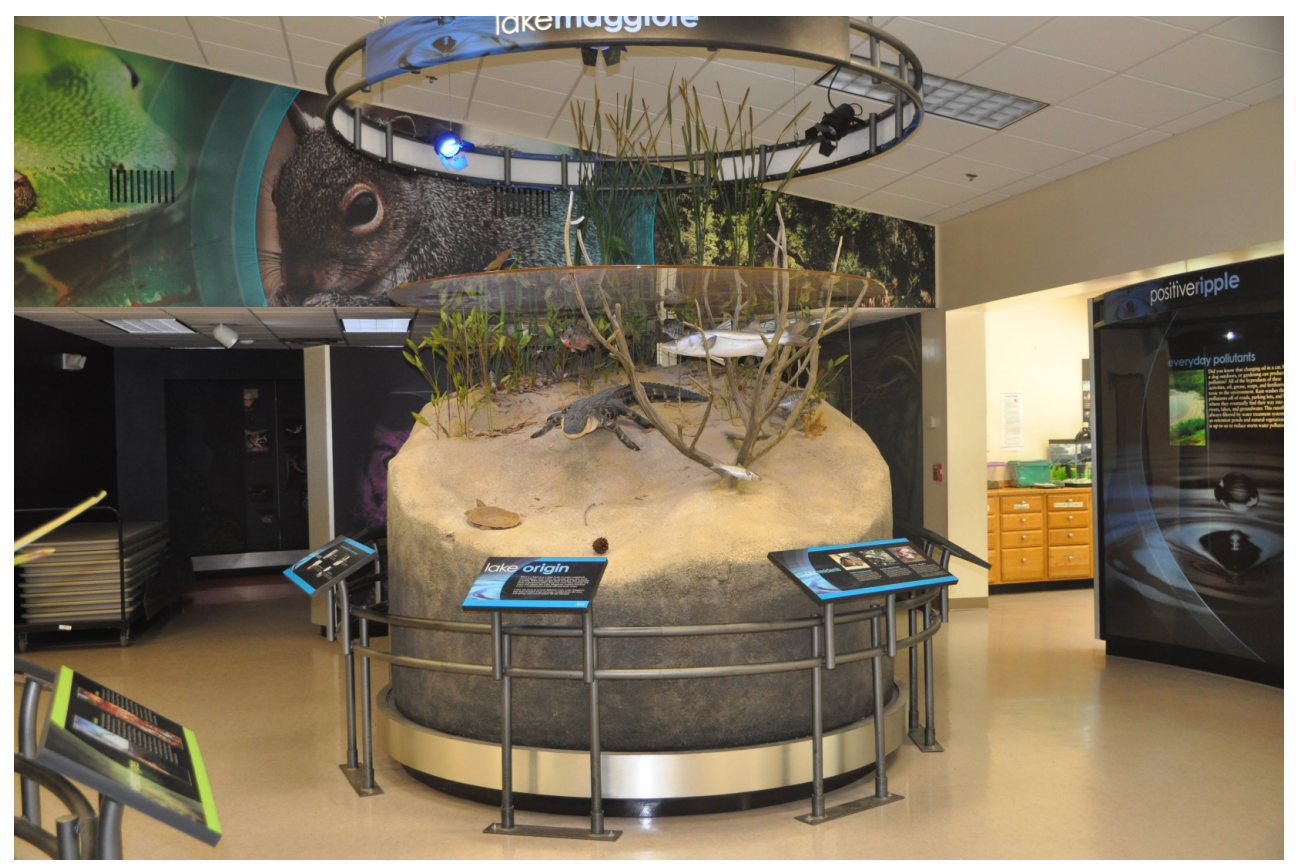

Figure 2: Boyd Hill Exhibit 


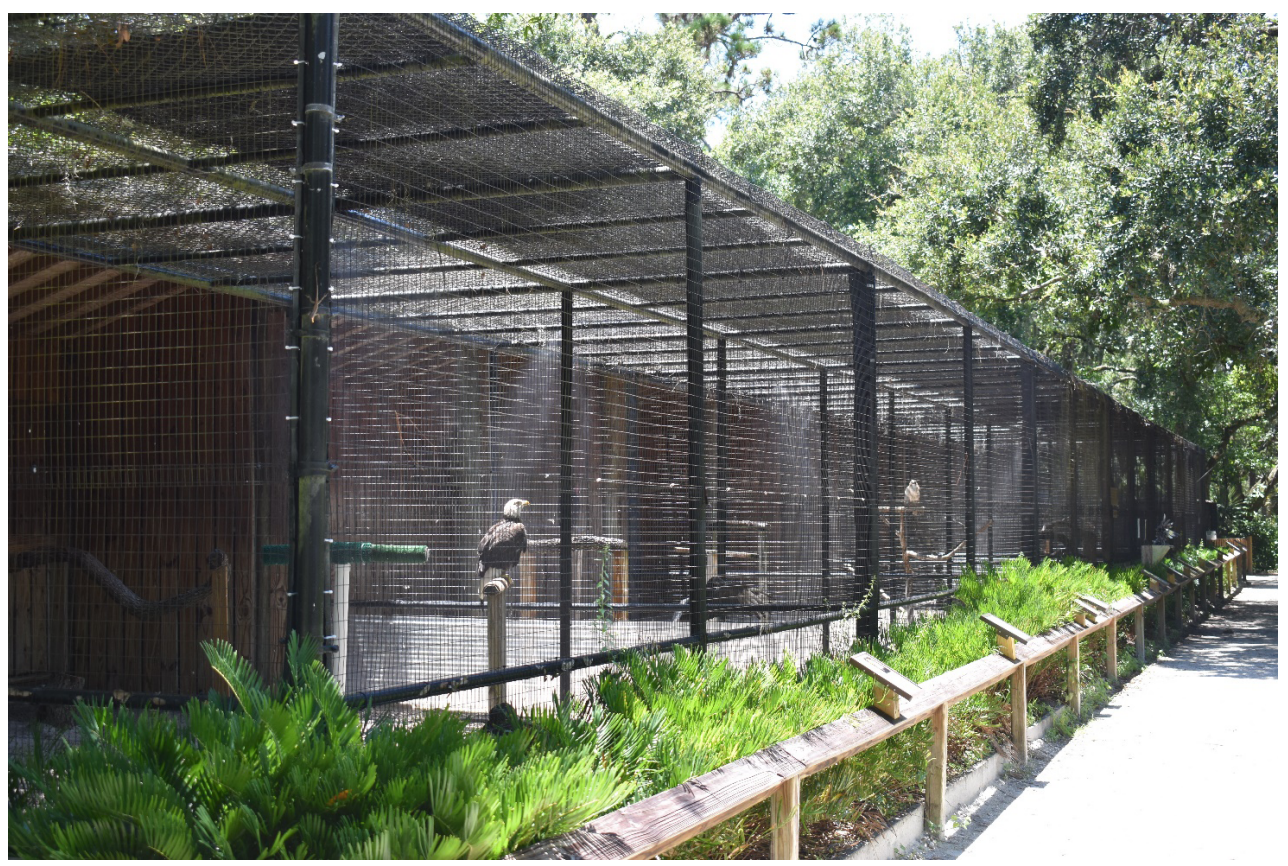

Figure 3: Boyd Hill Aviary

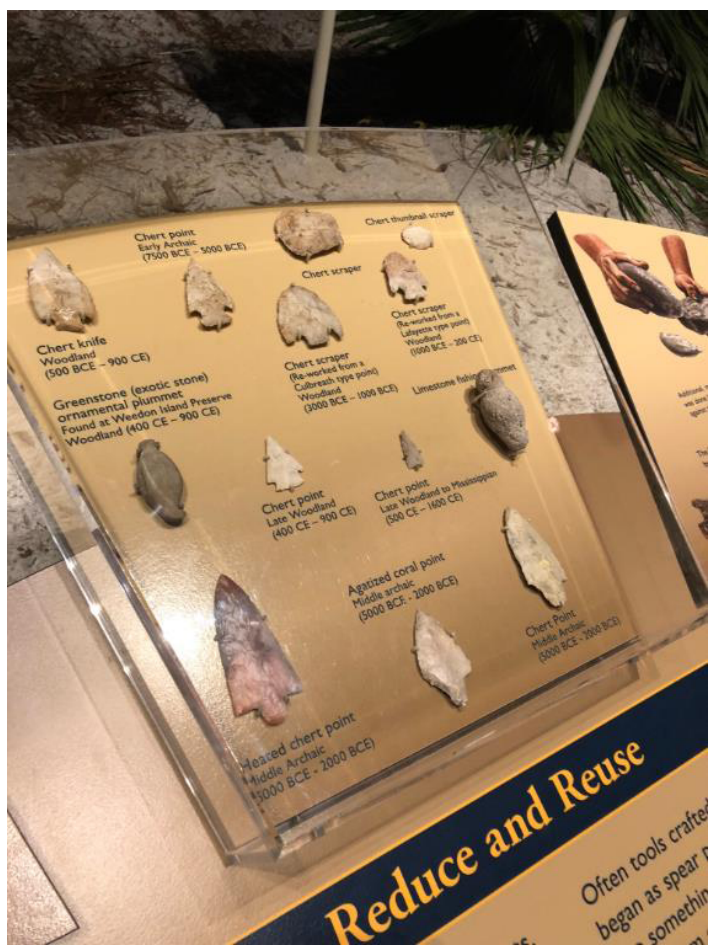

Exhibits at WI can be divided into two parts. The first part is devoted to the Tampa Bay watershed, representing the mangrove and tidal flat ecosystems that surround the preserve and bay area. The second part of the exhibit focuses on indigenous cultures from the area and how they used the land, showcasing cultural and archaeological artefacts, including replicas of pottery, an archaeological tent and displays of arrow heads and other items related to archaeology (Figure 4). This emphasis on human culture makes Wl's exhibit distinctive compared to other preserve exhibits in the region.

Brooker Creek Nature Preserve $(B C)$ is a preserve of over 8,000 acres governed by the Pinellas County Department of Parks and Conservation Resources. Considered a 'wilderness island', it is surrounded by urban landscapes. The mission of the preserve is 'to empower citizens to improve their quality of life and establish a connection with their environment through researchbased educational programs focused on natural, cultural and historical resources'.

Figure 4: Arrowhead Display at Weedon Island 


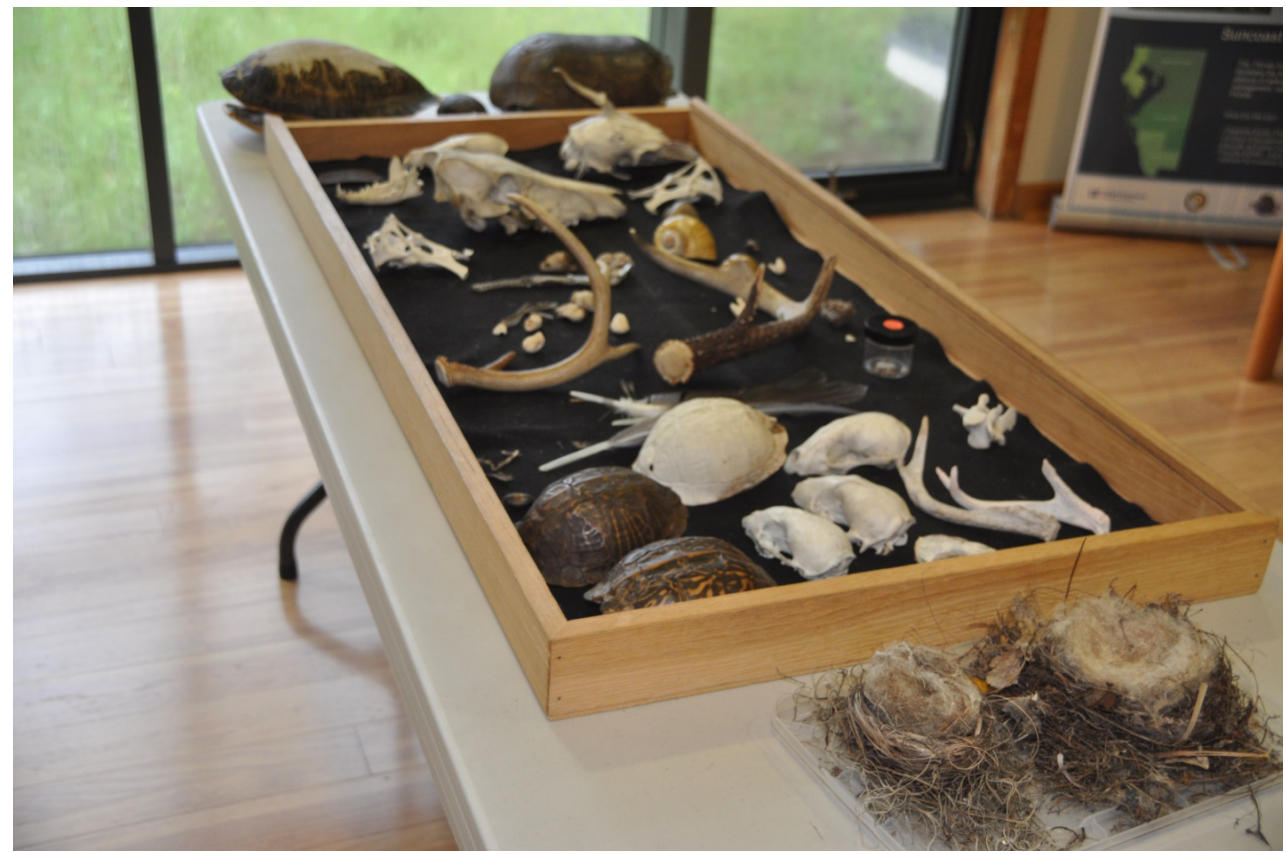

Figure 5: Animal Remnant Touch Table at Brooker Creek

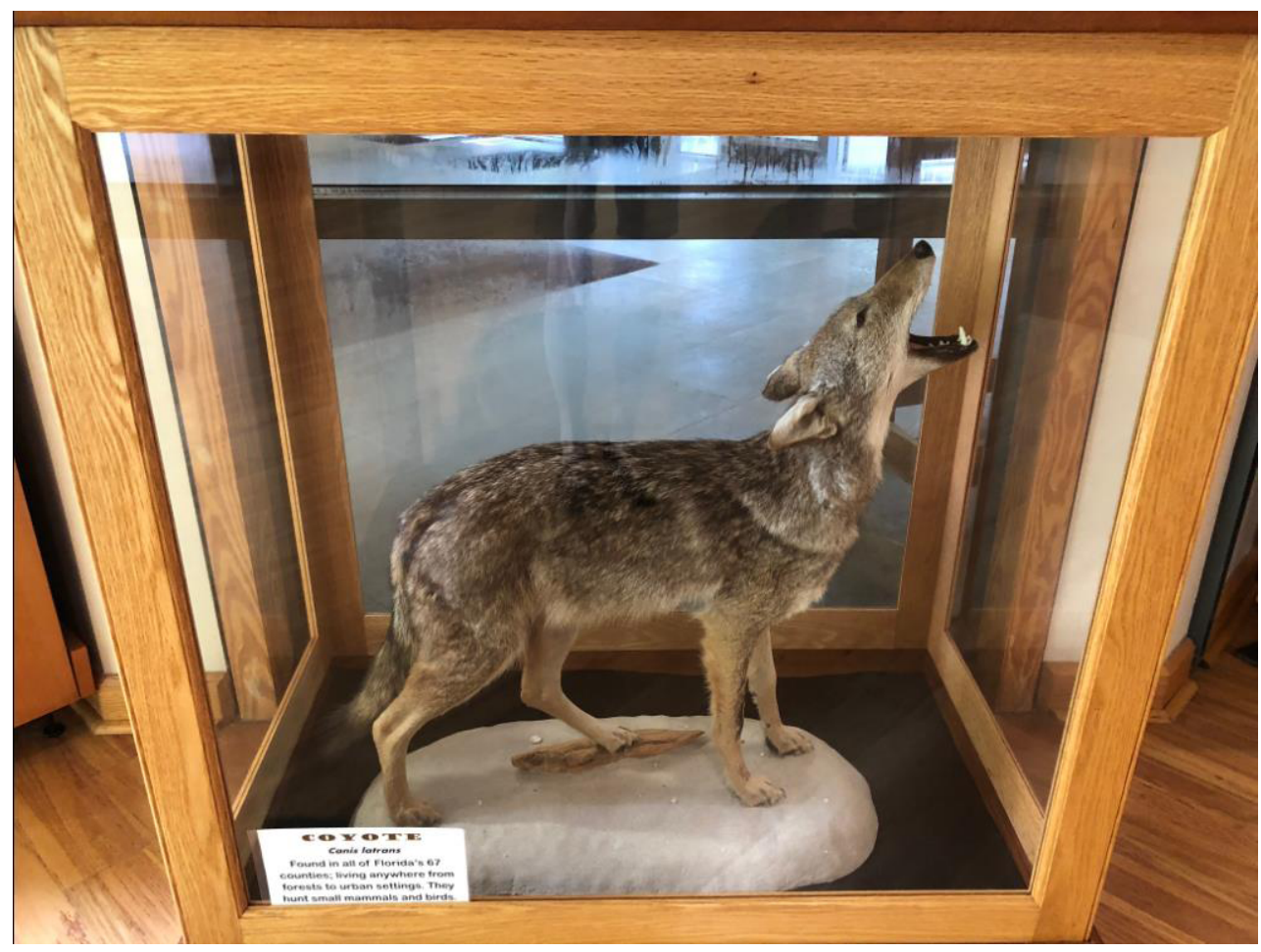

Figure 6: Taxidermy of Coyote at Brooker Creek 
Brooker Creek houses a 25,000 square foot education centre, including a 6,000-foot exhibit area, an auditorium and classrooms. The educational centre is divided into four areas, with the first area housing two touch tables covered with animal remnants (Figure 5), an interactive animal track display, and several cases with taxidermized animals (Figure 6).

The second area is a large room with a high ceiling featuring a 15 foot glass-encased miniature display of the landscapes of the region, offering a side by side contrast of the natural ecosystems (left) with human altered landscapes (right). The third area is a meandering exhibit that walks visitors through Florida's seasons, introducing seminal species, and explaining the role of fire and water in the landscape. The fourth exhibit area is an entomology room containing displays of butterflies and beetles; the centre also features a small theatre, in which a floor to ceiling video screen is surrounded by artefacts from an old barn. A video runs every ten minutes and introduces the viewer to a brief history of the changing uses of the land which constitutes the preserve today.

\section{Methods}

Multiple field visits to each preserve were conducted by both authors over six months from 2018 to 2019. Researchers visited each park alone and together. Photographs of exhibits and field notes were taken by each researcher separately. More than 300 photographs were taken, enabling researchers to continue to study exhibits after leaving the sites. Researchers engaged in all interactive opportunities presented at each exhibit and kept field journals of these experiences. Informal conversations with educators at the preserves were also conducted to clarify historical aspects and some processes of construction for exhibits.

Photographic and textual data were analyzed for each site, and then compared across sites. Exhibits were visually examined in person and again through the photographic record. Textual data, including signage, labels and field notes, were coded and analyzed using accepted qualitative analysis techniques (DeWalt and DeWalt 2002; Saldaña 2015).

Ideological rhetorical analysis (Foss 2009) was used to identify the dominant normative paradigm constructed by visual and textual narratives. For our analysis, the conceptual positioning of citizens in relation to the non-human world is central; exhibits may reflect an ideology of human dominion over nature. Conversely, they may destabilize this hegemonic discourse by presenting an alternative philosophical position of species equity, or perhaps, a middle ground of stewardship and an ethic of care. Simultaneously, the narrative may suggest a world in which citizens are primarily conceived as consumers, acting as individuals in a market world. Citizens might alternatively be constructed as members of a community, acting collectively on behalf of a larger biotic system. Keywords and themes were identified and catalogued for each exhibit. Coding searched for words and images that convey an actor (who is this citizen?) and an action (what should this citizen do?). Similarly, emotion and value coding were also conducted (Saldaña 2015), to identify words indicating a value placed on animals, ecosystems, natural processes and landscapes. We were attentive to language that conveyed feelings of connection and commitment, joy, love, sadness or outrage on the behalf of non-human nature. Visual analysis similarly sought cues in images and object displays to support specific ideologies of human-nature relationships as well as components designed to elicit emotional and behavioural responses in viewers.

\section{Four Foci of Analysis}

In framing our analysis, we draw from four focus points for best practices in EE: build knowledge, deepen understanding, gain skills and enhance sustainable behaviour (Monroe et al. 2008). These four points have been widely applied in the field and distinguish EE from science education by emphasizing the human relationship with nature and placing value on human behaviour that sustains the wider ecological community. EE moves beyond basic science education into the arena of action, agency, and responsibility - into the realm of citizenship. From museum studies, we draw upon four of Manubay and colleagues' (2002) list of criteria to evaluate permanent scientific exhibits: information - to introduce visitors to environmental issues and behaviours; engagement - to excite visitors about conservation behaviours; motivation - to develop and incite visitors' environmental responsibility; and participation - to 
offer visitors opportunities to explore environmental behaviours. Clearly, providing information is fundamental to any educational display and we would expect that exhibits provide substantial information about local ecosystems, natural processes, and flora and fauna. Engagement affirms EE's emphasis on outdoor learning and active pedagogy as well as emotional, physical and cognitive aspects of learning; participation affords visitors the opportunity to co-create narratives of the environment and identify opportunities for action. Motivation echoes the emphasis on moving citizens toward sustainable action on behalf of the environment.

While the provision of information through interactive learning opportunities is a fairly standard element of both museum and EE displays, concepts of emotional engagement and environmental citizenship are both more nuanced and complex, and require further elaboration here.

\section{Emotional Engagement/Affect}

A growing interest in the role of affect and emotion in learning at heritage sites and museums emphasizes the activation of audiences' 'ethical and political imaginations and... attentiveness to otherness' (Mulcahy and Witcomb 2018:214). Affect may be leveraged to motivate audiences, through a deeper emotional engagement with the past, to act in the present or for the future (Witcomb 2013). Chakrabarty (2002) argues that traditional knowledge production, relying on analytical processes, is no longer sufficient to engage contemporary audiences and advocates for more democratic, embodied and sensory experiences. While heritage museums often seek to uncover truths about a community's collective past, natural history museums are better positioned to address large scale human-nature relationships. Exhibits which evoke joy, awe, empathy, and even love, as well as sadness, anger or outrage, can be critical tools in motivating citizen action on behalf of nature.

Unlike contemporary natural history museums, park exhibits often contain live animals. Emotional engagement is also an important factor in institutions that display live animals, such as zoos (Bulbeck 2005). Indeed, live animal encounters may spark deep reactions in visitors (Mazur 1998; Ballantyne et al. 2011; Jacobs 2012). Thus, understanding opportunities to leverage affective engagement on behalf of nature is an important element in the analysis of park exhibits.

\section{Environmental Citizenship}

Concerns identified in the museum literature about the power of institutional storylines to reinforce human exceptionalism and reproduce models of change narrowly reliant on the disciplining of individual behaviour are echoed in the environmental citizenship discussion. Indeed, common approaches to the construction of 'citizenship' perpetuate a model of the citizen as a universal, property-owning individual characterized by 'autonomy, rationality, self-determination', and clear boundaries between public and private spheres (MacGregor 2006: 103). Throughout the 1980 s, the privatization of responsibility and the promotion of selfregulation as the main approach to environmental solutions nearly eliminated any pressure on either governments or corporations to act on behalf of sustainability. Environmental citizenship discussions have emphasized individual duty over notions of environmental rights and collective action.

Creating active environmental citizens has become an important goal of EE programming. While the notion of environmental citizenship has been debated and discussed at length elsewhere, we begin with Berkowitz et al.'s definition (2005: 228): '[E]nvironmental citizenship can be defined as having the motivation, self-confidence, and awareness of one's values, and the practical wisdom and ability to put one's civics and ecological literacy into action'. Furthermore, developing environmental citizenship requires moving beyond the private realm of personal choice and engaging with collective action in the public sphere for the common good (Berkowitz et al. 2005; Schild 2016). Building programs that motivate citizens to engage collectively in facilitating wider structural changes (through the revamping of public transportation systems, advocating for governments to aid in a transition from fossil fuels to renewable energy) is essential. Environmental citizenship conceptualizes humans as members of a larger ecological community and can challenge dominant values based on human exceptionalism 
and dualist ideas of humans as separate from nature. Szerszynki (2006: 78), for example, offers a more radical notion of environmental citizenship, in which commitment and loyalty to a larger bio-community leads people 'to think of the good of society in the abstract and thus in some sense to leave behind one's private identity and interests'. Particularly relevant to the study of material exhibits and their normative messages is the idea that citizenship is thus partially materialized through public acts of seeing and being seen; of engaging with material artefacts and visual and textual information, and a sense of participating as part of an audience. As visual badges of green citizenship, one may wear hats, t-shirts, pins, or carry flags or totes with environmental emblems. Further, one 'senses being part of an audience' (Szerszynki 2006: 78) through reading, listening, attending lectures and films about the environment, or visiting educational displays. Engaging with EE exhibits at local preserves could be an important part of the production of green citizens if park curators can leverage an appropriate balance between cognitive and affective learning elements, challenge hegemonic and hierarchal discourses about human control over nature, and introduce more democratic, polyphonic and trialogic (Cameron 2015a) thinking and speaking processes into their exhibits. Thus, our working definition of the environmental citizen is one which combines knowledge, commitment, and personal as well as collective action for the environment that moves beyond mere personal behavioural change. Specifically, we look for opportunities for exhibit visitors to be emotionally motivated to act to ameliorate environmental problems through individual and structural transformation.

\title{
Exclusion and Inclusion
}

Environmental citizenship must also be socially, economically and racially inclusive in order to be effective. The bias in nature preserve visitor demographics is well-documented and discussed (Taylor 1989; Byrne and Wolch 2009; Finney 2014); recent work has investigated the exclusion of lower-income and racial minority groups from science museums (Dawson 2014). Dawson notes that:

\begin{abstract}
Visitors to ISE [informal science education] institutions come from more affluent, middle-class backgrounds, from ethnically dominant backgrounds... live in urban areas, and visit as part of a school or family group... Research suggests that informal science learning resources cluster around such groups (Dawson 2014: 982).
\end{abstract}

Research attempting to explain the exclusion of working class and minority groups from informal science experiences has tended to focus on a 'barriers' approach; however, when financial barriers (entrance fees) were removed, studies found that overall numbers of visitors increased but diversity did not. Families from Latin-American backgrounds were reported to find science centres 'unwelcoming, expensive, and difficult in terms of the language used' (Dawson 2013: 6). Social distance, the sense that science centres 'aren't for me', was a major factor in preventing non-white communities from visiting ISEs. Dawson's participants agreed that ISE institutions were for visitors who were 'white, middle-class and wealthy' (Dawson 2014: 1002). Ample research indicates that minority communities are less likely to visit nature parks and preserves and often feel excluded from natural spaces by cultural heritage, signage, advertising and the behaviour of park employees (Byrne and Wolch 2009; Finney 2014). Pinellas County's population is 76 per cent white; however, the county is quite segregated, with neighbourhoods in south St Petersburg, where Boyd Hill Nature Preserve is located, consisting of predominantly African-American residents. Including ethnically and economically diverse populations in the conceptualization of the environmental citizen is an important goal and has implications for exhibit design.

\section{Roadmap}

Blending shared concepts from museum studies with critical concepts in EE and environmental citizenship provides a theoretical road map for the analysis of material exhibits at the study sites through the emergence of four conceptual foci. The first area of analysis identifies 
efforts to share knowledge about the environment and increase understanding of ecosystem processes and components, including human interactions with local landscapes. Secondly, we seek opportunities for learners to participate in constructing knowledge, becoming creators of environmental narratives through interactive exhibits. Next, we identify exhibits that use emotional engagement to connect with and motivate audiences on behalf of nature; and finally, we look for suggestions of sustainable action by environmental citizens to solve environmental problems. Ideally, citizenship messages should destabilize complacent views of the human-nature relationship and create a sense of urgency and desire for change. We identify sustainable actions that are in the realm of the personal and individual, and those that are in the realm of the collective and structural.

\section{Exhibition Analysis}

In this section, we evaluate the overall impact of each preserve's exhibits within the four foci of knowledge, participation, emotional engagement, and sustainable action through environmental citizenship. This latter category carries the most weight, for this is where the exhibit narratives may - or may not - challenge a market ideology that tends to position citizens as individual consumers acting only in the private realm, encouraging inclusivity and collective action for environmental change.

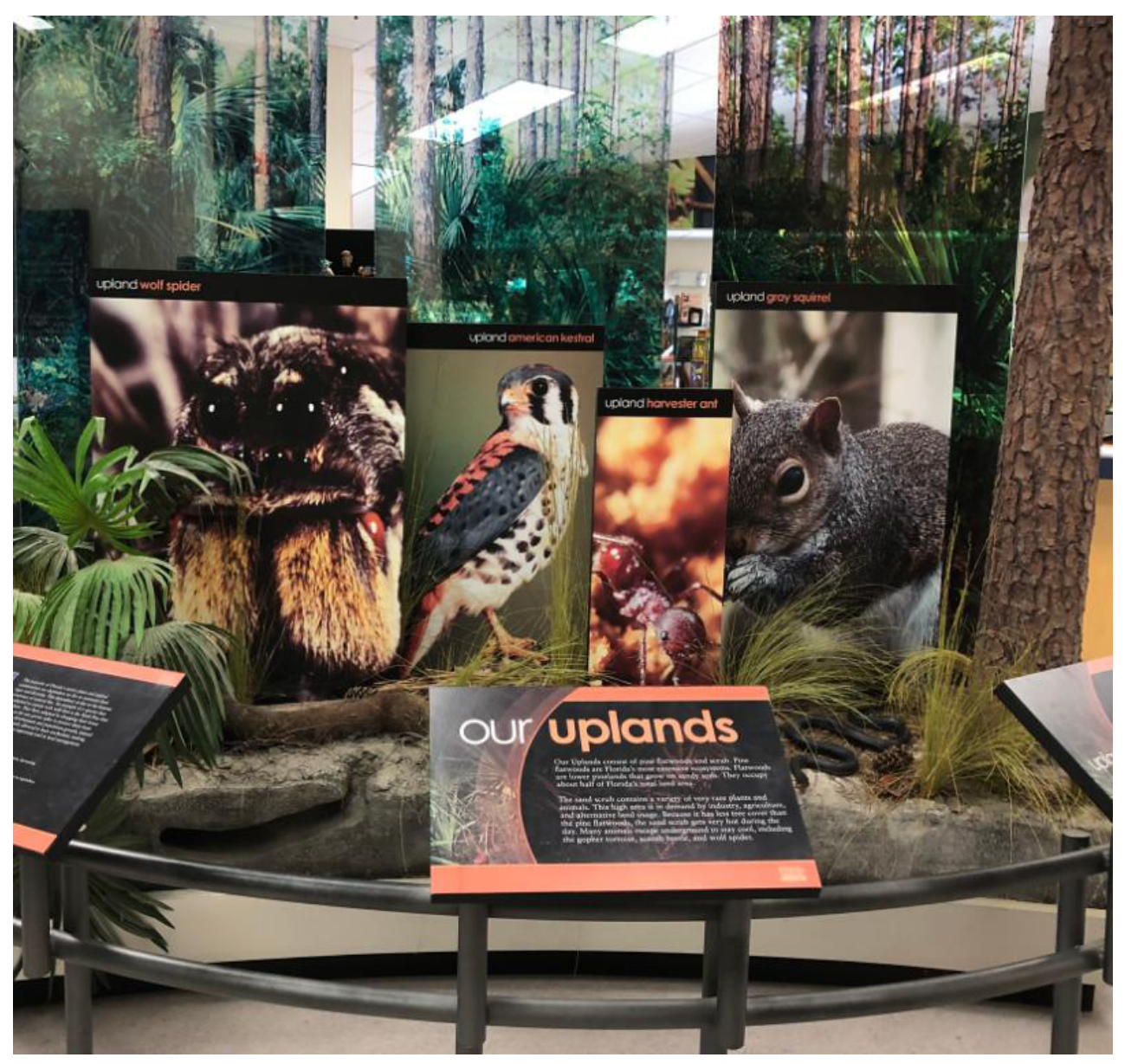

Figure 7: Visual and Textual Displays at Boyd Hill 


\section{Knowledge}

Boyd Hill's exhibit contains factual displays that encourage cognitive engagement with local environmental knowledge. These messages are delivered primarily through manufactured displays with textual and visual information (Figure 7) and through labels for visual and touch displays. Information covers multiple species of flora and fauna. Systems level information covers wetlands, uplands and lake ecosystems and the Lake Maggiore watershed. The theme 'ripple effect' unifies the exhibits with an emphasis on interconnections and entanglements, including a strong focus on human impacts on the land and its inhabitants. For example, visitors are told 'when a plant or animal in an ecosystem is harmed, the damage is felt by all other species'. Further, 'the most important part of creating a positive ripple effect in the lake is by changing our behaviours'.

Human impacts on the lake bordering the preserve are a significant focus of the exhibit. Using frequent questions, exhibits draw observers into conversation with artefacts on display. Signage stating, 'Did you know that changing oil in your yard, bathing a dog outside, or gardening can produce water pollution?' sits above an interactive exhibit in which visitors open a series of decorated boxes (Figure 8) and read the information inside. Each box indicates a specific type of lake pollution; as the box is opened, a GIS map lights up on the display to show spatially how the pollutant enters the lake (Figure 9). Personal responsibility is a prevalent theme:

Fresh water is a precious resource that we can help protect. Every one of us contributes pollution to our streams, lakes, bays and oceans. The wastewater, dirt and debris from human activities eventually drains downstream into our oceans. When we are aware, we can reduce the amount of pollution we cause.

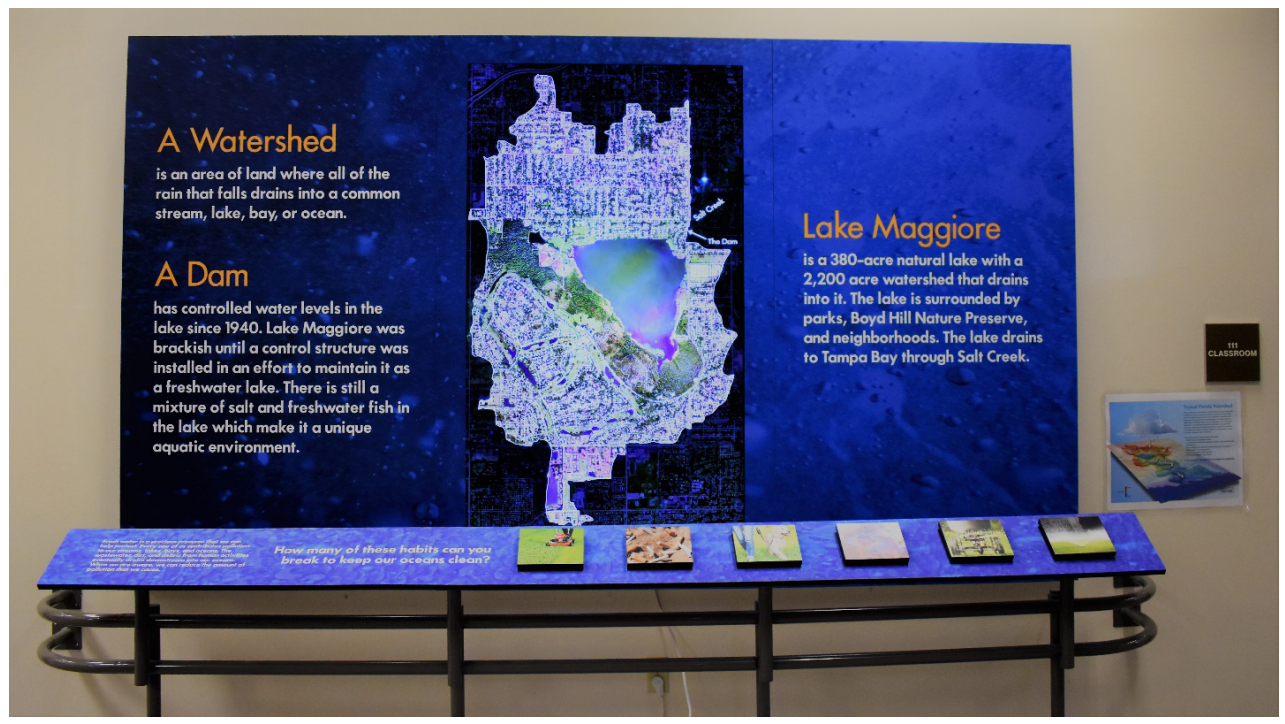

Figure 8: Interactive Box Display at Boyd Hill

Animals are a prominent focus of all exhibits at $\mathrm{BH}$. They permeate the primary display area, and are the main focus of the secondary display area, where turtles and snakes are housed, bright photos of the local fauna line the wall (Figure 10) and the alligator skeleton resides (Figure 11). Signs explain the history of the American Alligator, its endangerment and actions that led to the species' recovery, as well as the plight of this specimen. At the rear of the primary exhibit area is a large gopher tortoise display. The display includes substantial information about the species, noting that '[b]y continually developing land, humans are fragmenting and decreasing the habitat available to tortoises'. Humans are invaders, an outside force that has negative impacts on an external nature. 


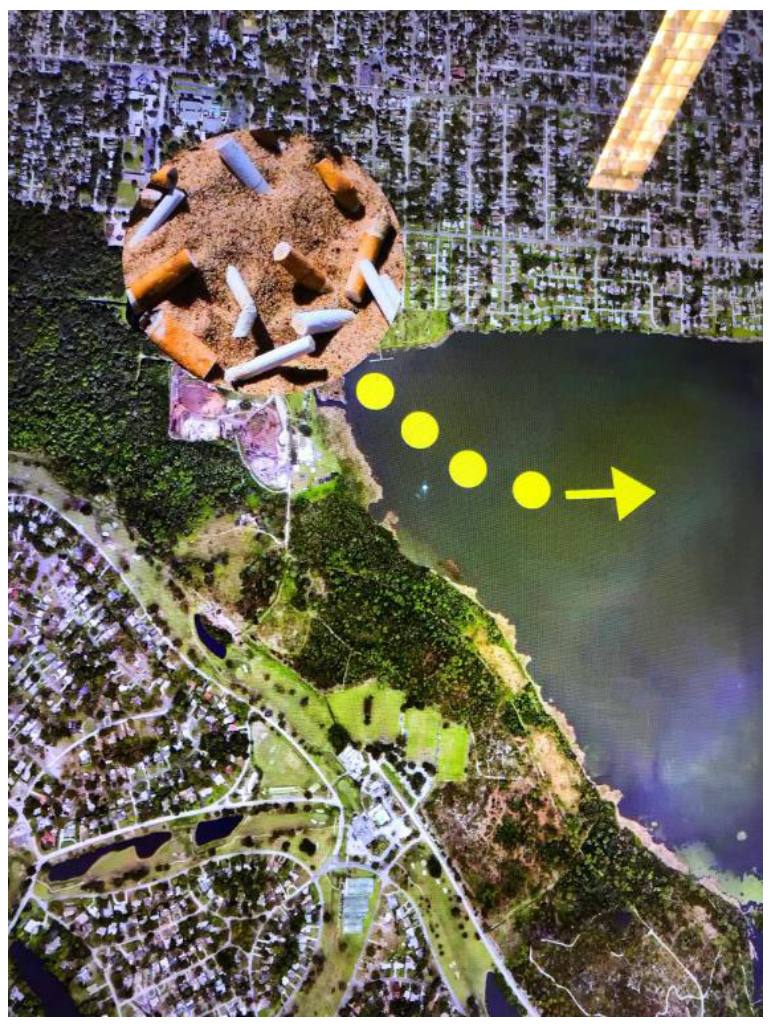

Figure 9: GISMap with Interactive Box Displayat Boyd Hill
Brooker Creek's exhibit also contains factual knowledge about local ecosystems, species and changes in the land due to human influence. Specific data (habitat, lifespan, dietary and nesting habits) about selected species such as bobcats and gopher tortoises is displayed on wall boards, next to taxidermized or manufactured displays. Change in the landscape resulting from human impact, including deforestation, urban development, cattle ranching, the turpentine industry, and residential landscaping are all major themes. Perhaps because the land area of this preserve is significantly greater than that of $\mathrm{BH}$, the curators were able to include more systemic and large-scale processes of land use change in their narrative. While the focus here on large scale systems is positive in that it moves away from a model of citizenship based solely on individual behaviour, the role of humans as master manipulators of nature (seen here as a collection of resources - soil, timber) is the dominant theme.

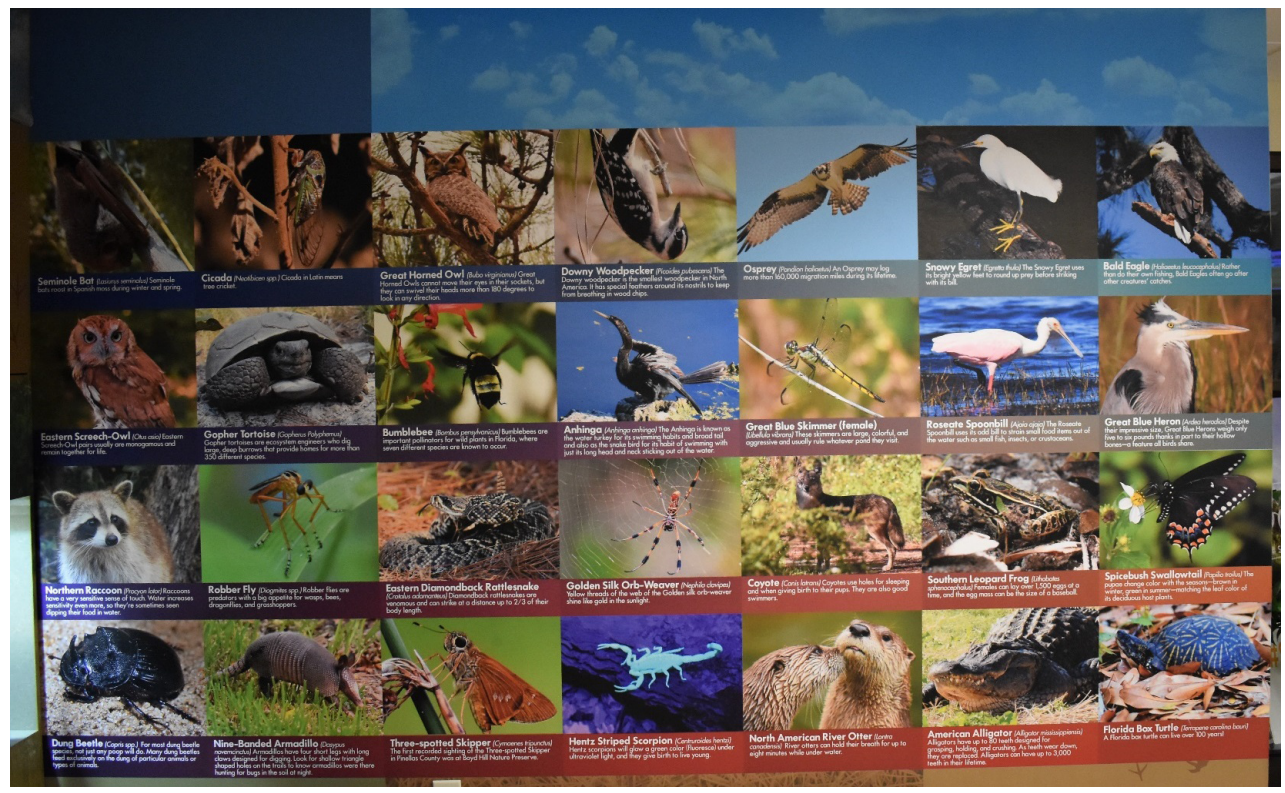

Figure 10: Animal Exhibit Wall at Boyd Hill 


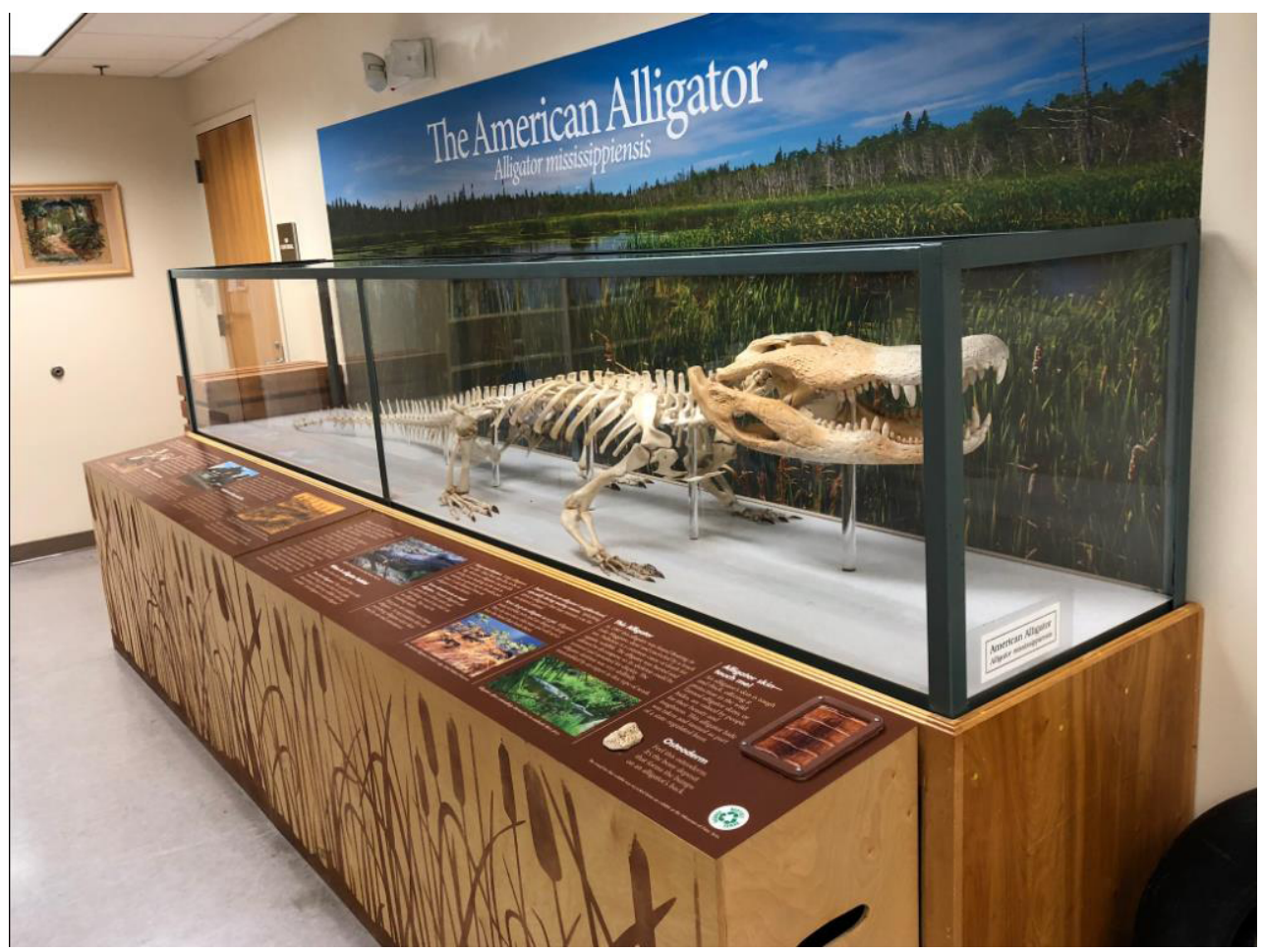

Figure 11: Fourteen Foot Alligator Skeleton at Boyd Hill

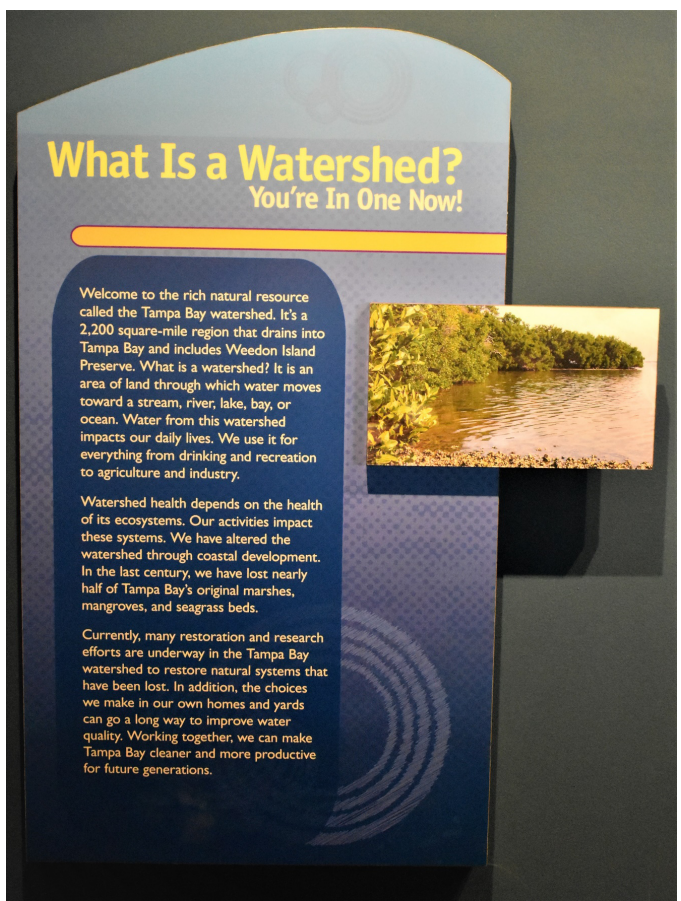

Weedon Island's exhibits present facts and knowledgeabout theenvironment, with a focus on management and the importance of the park's natural resources to society. Most of the textual displays contain suggestions for action at the end of a long, information-packed paragraph (see Figure 12, for example). The tendency to display dense textual labels may detract from the effectiveness of the exhibit (Falk et al. 1986: 506).

Humans are very much present in the narrative of Wl's exhibit. Much of the display focuses on human actions, and half of the exhibit is devoted solely to human culture, highlighting the connection between humans and nature (Table 1).

Figure 12: Textual Display on Watersheds at Weedon Island 
Over two million people live in the Tampa Bay watershed! As the population continues to grow, it increases the need for fresh water. To meet this need, changes are made to Tampa Bay to help provide fresh water to people. Some of these changes may create stress on the estuary. Understanding these effects will help us better manage our water supply.

Anyone who has fished in Tampa Bay or eaten seafood at local restaurants will appreciate the value of plankton. As the staple of the estuary food web, plankton support our local fishing industry.

Our goal is to restore the benefits of natural systems for wildlife and humans. To achieve this goal, we continue to piece together the restoration ecology puzzle.

Table 1: Examples of text from Weedon Island that promote human nature connection

All three parks present ample factual information about the ecosystems, flora and fauna within their boundaries. Additionally, negative impacts on the environment from human activity are highlighted. The narratives have strong undertones of humans as managers or influencers of the environment, reaffirming traditional dualism and separating the human realm from the rest of nature.

Indeed, the aspect of Wl's exhibit that tells a story of humans as deeply embedded and entangled in nature is the section on the indigenous people of the area. Dioramas in this section display Seminole and Calusa people living in the pine barrens and coastal zones, using local resources while leaving little behind in terms of changes to the landscape. While this narrative may inadvertently echo much disparaged tropes of the ecological savage (Hames 2007), the stark difference in representations of the human-nature nexus is insightful. In juxtaposition to indigenous people, 'modern' humans are presented as separate from nature, positioned as manipulators of the natural environment through both stewardship and destruction. Within Wl's exhibit hall, people moved out of nature, away from a symbiotic relationship with the living landscape, and into a position of power and control. Thus, the story of modernism, with its core message of human transcendence of a fallen material world, is precisely replicated in the exhibit hall.

\section{Participation and Interactive Learning}

Boyd Hill's educational exhibit provides opportunities for visitor participation in learning through touch and interactive exhibits, such as a large, crawl-through, gopher tortoise burrow replica. Multiple touch opportunities are provided throughout the exhibit. Upon entry visitors are invited to touch feathers and other items such as snake moults on a small table. An exhibit of a fourteen foot alligator skeleton also has a small section of alligator skin for guests to feel. Additional interactive exhibits include a watershed display that encourages viewers to manipulate the amount of rain falling in a physical model of the area made from sand. Two exhibits require visitors to open boxes or drawers to discover answers to questions or view and touch collected items such as shells, bones, rocks, and plastic replicas of animals (Figure 13).

A second opportunity for further physical engagement with animal artefacts is placed deeper within the primary exhibit as part of 'The Birds on the Wing' display. This display consists of feathers, bones, skulls, and talons of dead animals complemented by a striking manufactured sign with graphic representations of birds which highlights migration patterns and dangers faced by birds migrating to or through Florida.

Brooker Creek's exhibit is also highly interactive. Visitors are invited to touch animal skins, shells and bones; create animal tracks in a sandbox; manipulate a digital map of the watershed; immerse themselves in an experiential video; and climb through a gopher tortoise burrow display, similar to the one at $\mathrm{BH}$ (Figure 14). 


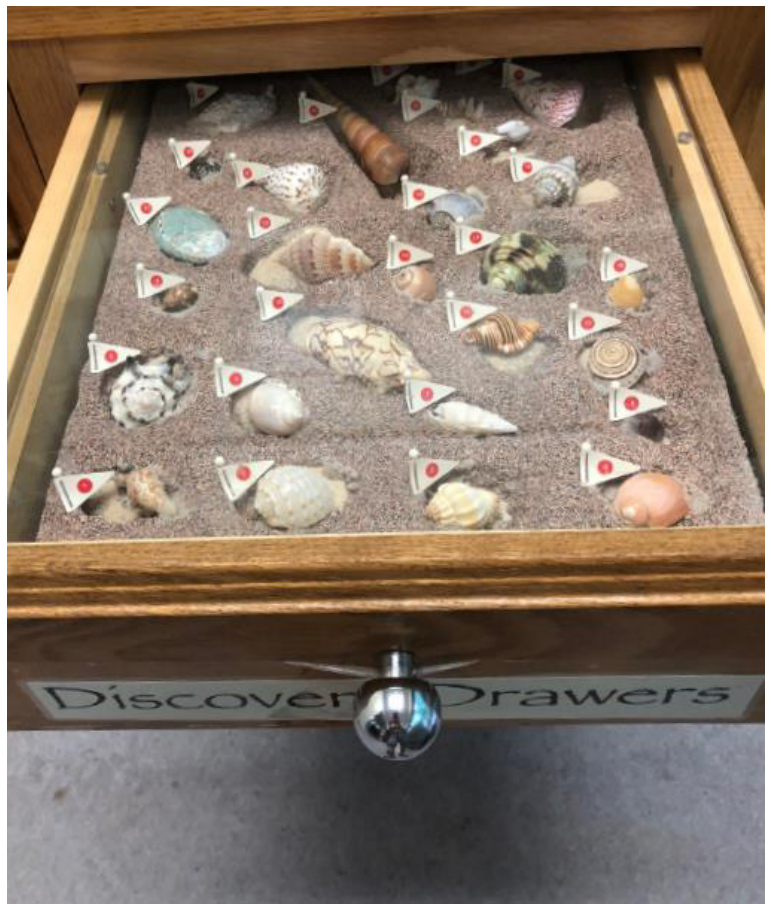

Figure 13: Discovery Drawer at Boyd Hill
The exhibit's Florida Friendly landscaping display is also interactive, featuring large, colourful three-sided blocks which spin. The blocks can be aligned to show a traditional yardscape vs. a Florida Friendly native yard. Additional signage lists steps people can take to transform their living spaces into native wildlife habitat, reminding visitors that 'wildlife needs a place to call home, too'. In this display, humans are positioned as stewards of an embattled nature.

Displays make good use of questions to draw visitors into conversation with the material artefacts. For example, the miniature diorama of the area asks 'Have you ever wondered if it is wise to build right along the shoreline? If you were a wading bird, what would you want the shoreline to look like?' Asking observers to think like a bird opens the possibility of a deeper connection between humans and non-human others.

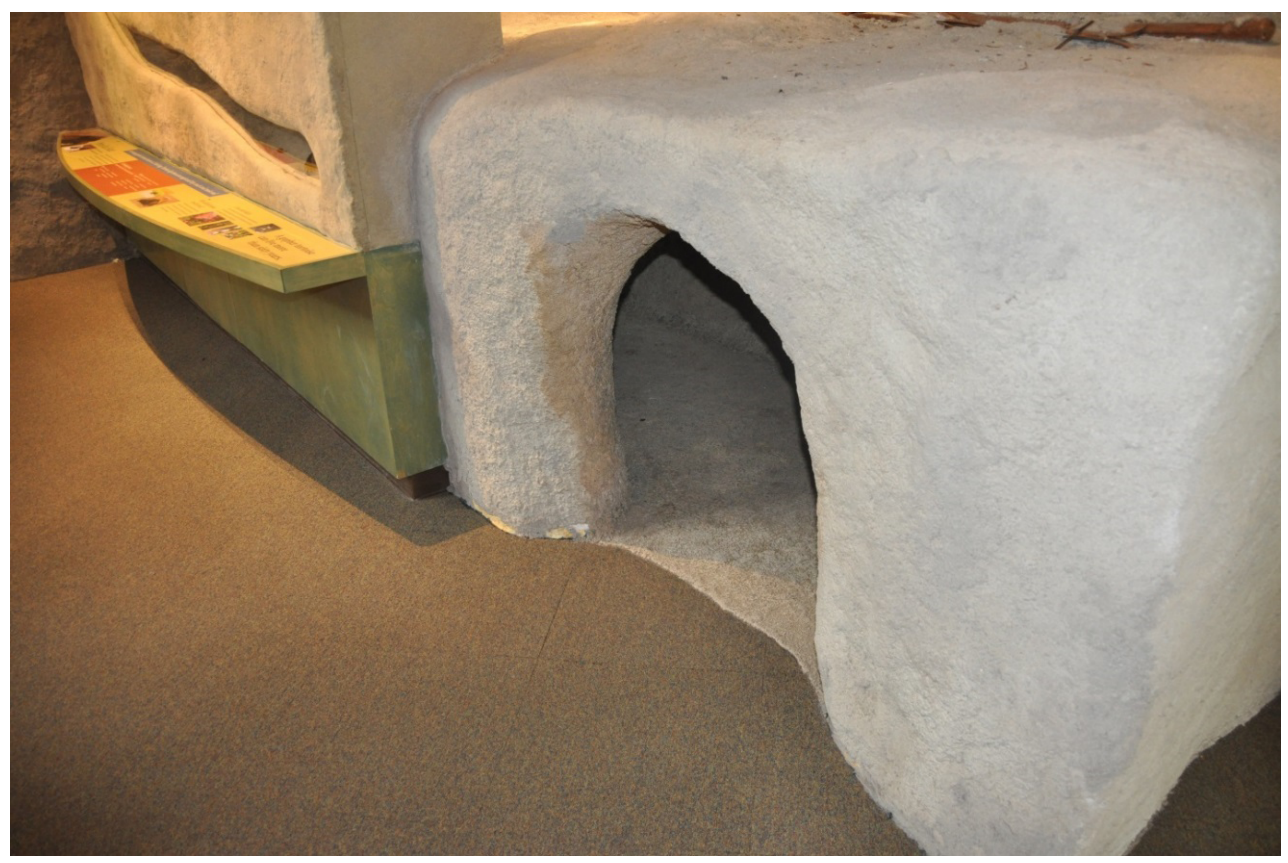

Figure 14: Interactive Gopher Tortoise Burrow Display at Weedon Island 
The 'Shopping Central' section of the diorama tackles the urban development necessary to provide easy access to products for our consumer lifestyles.

Do you know that sunbaked city concrete can heat the local air enough to cause thunderstorms? Paying for Convenience: We want lots of things, and we want them nearby. Traditionally, this has meant the loss of natural areas and more pavement. The result: increased flooding, polluted runoff, less water recharge and loss of wildlife.

By addressing the audience directly and personally, the exhibit invites visitors into the environmental narrative, encouraging the individual to make value judgements about what is best for local ecosystems and their inhabitants, thus attempting to transform guests into agents. While this engagement is positive and can help develop visitors' sense of responsibility for the environment, the narrative nonetheless positions humans as separate from nature. Humans are users and destroyers of the environment; there is little sense of the possibility of a more positive or entangled relationship between humans and non-human others.

Weedon Island's exhibits are somewhat interactive and encourage participation in a rudimentary form. Guests can rotate display signs for additional information, move panels within a display to uncover hidden images or textual information, push buttons to see the effects of an action, or assemble puzzles. However, several of the interactive exhibits were broken and inoperable. The preserve exhibits, however, have no touch opportunities with animal artefacts and no live animal displays. Only the bronze gopher tortoise in the reception area provided an opportunity to touch. All other replicated animal exhibits and artefacts were encased in polycarbonate, limiting bodily engagement with displayed replicas.

\section{Emotional Engagement/Affect}

Boyd Hill and Brooker Creek encourage emotional engagement by providing strategically placed information about the dire circumstances of charismatic animals and creating opportunities for sensory connection to living animals as well as the remnants of dead animals. By touching feathers, bones and skulls, visitors are reminded of the sentient, embodied nature of nonhuman animals. The very act of touching brings us closer to understanding that the "beast is no more' (Poliquin 2012: 7). Such encounters work on our longing for contact with animal others and can evoke curiosity, excitement, sorrow, and even compassion. The interactive touch component of the bird display offers an emotional connection with these once living creatures through examining and interacting with the bones, beaks, feathers and talons. Visitors are told:

The worst dangers to migrating birds... are man-made. The fragmentation of their range due to building and land development means less nesting and feeding areas for many birds. Millions of birds are killed every year flying into power lines, cell towers, and buildings. (italics ours)

Visual and vocal interaction with living animals through indoor live animal displays and the birds of prey aviary (Figure 15) further augments emotional engagement with nature. ${ }^{1}$

Displays may also use rhetoric to inspire visitors to action. Researchers noted that the $\mathrm{BH}$ exhibit contains one inspirational message, found on the right wall of the interior exhibit. The sign reads:

Stewardship: This we know. The earth does not belong to man; man belongs to the earth. This we know. All things are connected like the blood which unites one family. All things are connected. Whatever befalls the earth befalls the sons of the earth. (attributed to Tom Perry, AKA Chief Seattle).

The inspirational quote reinforces the theme of ripple effects and human entanglement with nature and gestures toward destabilization of culture/nature dualisms. Some inspirational messages at BC include 'Unless we change direction, we are likely to end up where we are going' and 'We cannot solve the problems that we have created with the same thinking that created them' (Albert Einstein). 


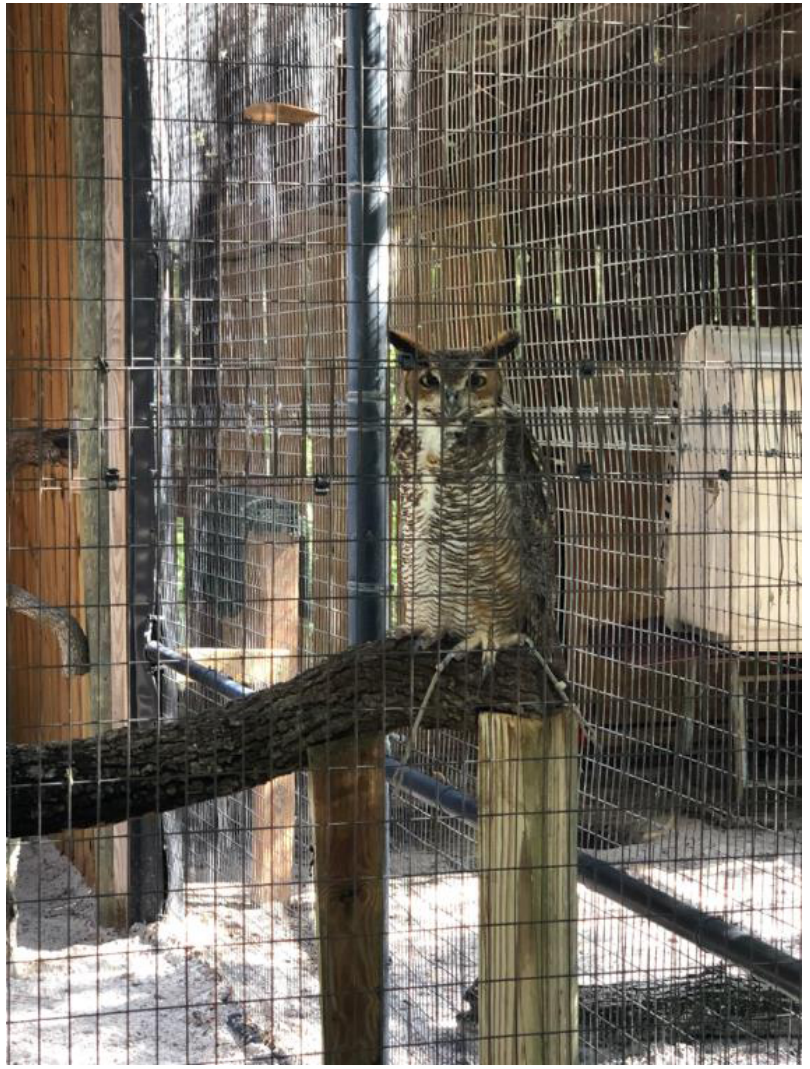

Figure 15: Aviary at Boyd Hill
Weedon Island hosted a single inspirational display titled 'You Can Choose Your Legacy' in which quotes are provided with regard to choices on the impact visitors have, the uniqueness of the environment and the importance of history (Figure 16). Wl's exhibits, however, tended to encourage a scientific and cognitive engagement with the environment over an affective one. These messages do little to remove humans from positions of superiority or control over nature. Environmental Citizenship through Sustainable Action

To understand how environmental citizenship is imagined, we need to ask who this audience/citizen is, and what they are asked to do. While all three preserves' exhibits contain action messaging to engage visitors to help protect the environment, the imagined audience is quite limited.

Most of the suggested actions favour homeowners, perhaps the middle-class residents of the surrounding neighbourhoods. While 67 per cent of households in the county are homeowners, 33 per cent are renters. ' 'Water your lawn early in the morning' clearly applies only to homeowners; 'install low-flow toilets and showerheads' may be beyond the control of renters; but 'wash only full loads of laundry and dishes' is something everyone can do. Carpooling and biking have wide application, while 'drive a fuel efficient car' applies only to those with the financial means. 'Take public transportation' is notably absent from the list. Landscaping with native plants and keeping one's boat clean of non-native hitchhikers are suggestions for a specific demographic and not applicable to a large section of the population. At $\mathrm{BH}$, visitors are told 'There are things people can do, too, to help conserve bird populations. Constructing bird houses, leaving dead or downed trees, gardening with native plants and not disturbing birds or their nests all help protect the birds'. Humans are imagined primarily as managers or influencers of a separate nature which is in need of our assistance.

Directives about composting, lawn care, and gardening are most relevant for homeowners with yards and not likely to be of interest to renters. Keeping tortoise burrows free of blockage just isn't a useful recommendation for most urban dwellers. Similarly, leaving downed trees or gardening with native plants are not actions that apply to apartment residents. While it may be the case that the majority of visitors to the preserves are, indeed, middle class homeowners, limiting the narrative of citizen action to this socioeconomic group misses the opportunity to reach other classes of people who may come to the preserve. Indeed, the lack of an inclusive vision of citizenship may be a barrier to diversifying attendees in terms of race and social class. While $\mathrm{BH}$ is located in a primarily African-American neighbourhood, over the past few years, discussions among park managers have focused on the lack of visitors from the local neighbourhood and what might be done to increase diversity in park attendees. ${ }^{3}$ 


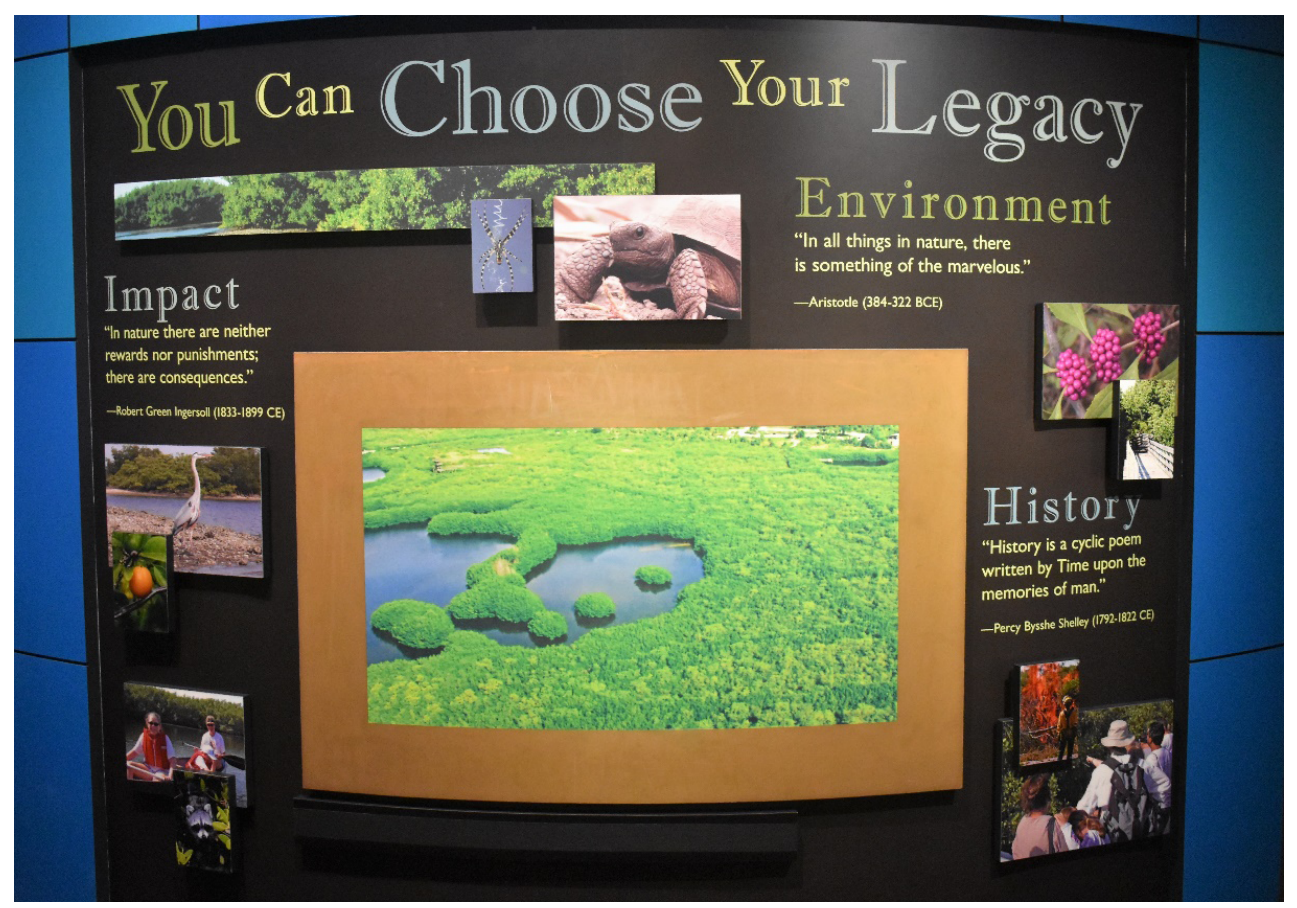

Figure 16: Inspirational Messaging at Weedon Island

In addition to demographic limitations on citizenship, displays tend to reinforce the narrow focus on individuals acting in isolation to change their personal behaviour. BH's main permanent display areas make suggestions directed primarily at the individual or family. Only one message was identified that suggested government or community action: 'Cities and towns can also help through better planning and management of runoff and wastewater' through an increase in retention ponds. Similarly, signage explaining that people can assist gopher tortoises by not disturbing them and not blocking burrows neglects any actions one might take to slow large scale development that results in habitat loss; this is a notable absence given that the City of St Petersburg is currently undergoing a sustained period of rapid urban development and redevelopment.

Suggested actions at BC contain expected admonishments about personal behaviour, including recycling, Florida Friendly landscaping and wildlife friendly yard design options. 'Scoop the Poop' signage disciplines pet owners. 'Leaving a strip of native vegetation between your home and the water', and 'Slowing down your boat near the shore' to avoid disturbing wildlife are clearly suggestions, like landscaping ideas, designed for homeowners and people in higher socioeconomic categories, but also position citizens as private consumers, rather than active public agents.

Weedon Islands' sustainable action messaging, while more limited, also emphasized individual actions to support conservation. Messages stressing the simplicity of the action often accompanied suggestions such as 'When we take small steps, both humans and wildlife benefit'. Examples of sustainable actions provided to guests include: 'reduce fertilizer use', 'avoid pruning mangroves', and 'never release pets or aquarium plants into the wild'. A video display titled 'Bring Out the Wild Side' highlight ways to make a nature-friendly backyard. The self-regulatory aspect of these messages is quite apparent. Further, the narratives construct humans as above and separate from other aspects of the living environment, as stewards and decision-makers for nature. There is no sense emanating from the displays of humans as embedded in a 'community of beating hearts' (Corbett 2018). 
Collective and systemic action on behalf of the environment is largely absent from the displays. At the time of this research, however, $\mathrm{BH}$ hosted a temporary exhibit on plastics created by a student as a school project. This exhibit's suggested solutions to the problem were comprehensive and structural, highlighting prevention and recovery. Prevention included: stop using plastic straws; support businesses that cease using plastic straws; support legislation to ban plastic straws; and finally, 'push for policy change'. The curator suggested attending a beach clean-up and joining an environmental organization under the heading 'recovery'. The open encouragement of visitor participation in structural-, community- and societal-scale change indicated here is very promising. While the messages begin at the level of citizen as consumer, they expand into a broader arena of action.

Other major environmental problems such as deforestation, resource depletion, overconsumption, air pollution, water scarcity, waste production (other than plastics) or energy problems are absent from BH's exhibits. No mentions of industrial development or commercial agriculture are made. It might have been difficult for the curators to make the connection between the preserve's ecosystems and such large-scale challenges, given that preserve exhibits tend to focus heavily on place, and $\mathrm{BH}$ is relatively small. As we have argued elsewhere (Johns and Pontes 2019), the place-based character of nature preserves may limit the scope of their educational engagement with national or global scale environmental processes if such processes are not clearly manifest within the geographic boundaries of the preserve. While a single exhibit cannot be expected to adequately address all environmental problems, the nearly complete lack of reference to large scale degradation and resource depletion in park exhibits is a notable omission.

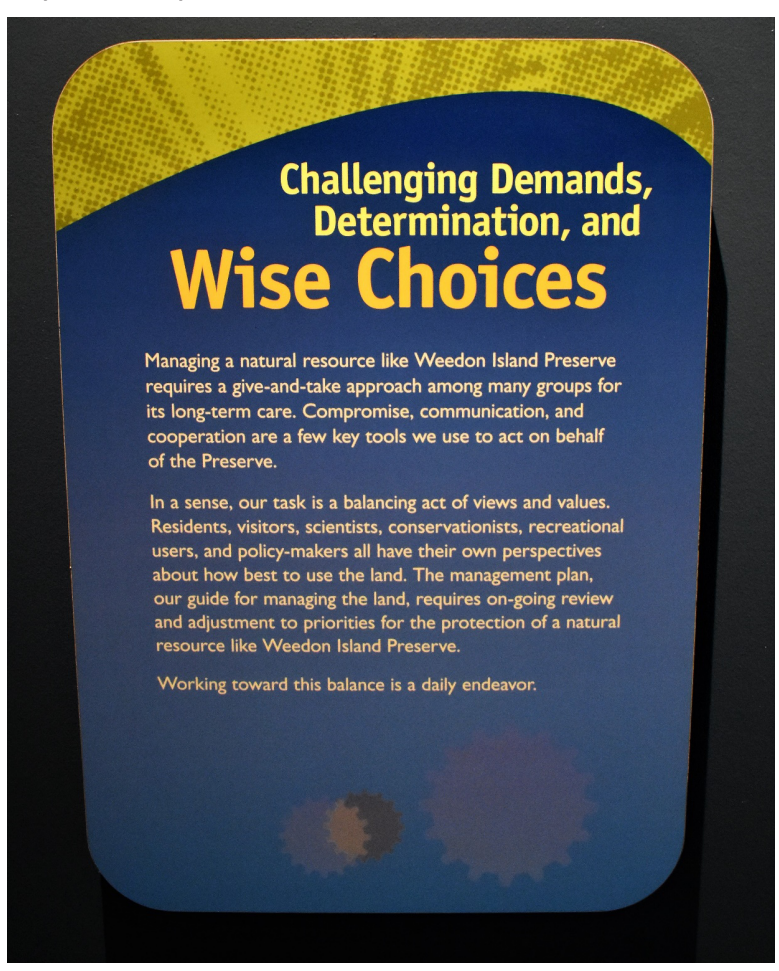

While messaging at WI was primarily focused on individual action, the 'You Can Help Save the Bay' exhibit gestures toward collective action. Signage explainsa collaborative and continual process of negotiating the management of the preserve with a variety of community stakeholders (Figure 17 ), encouraging a higher level of involvement in environmental protection by suggesting 'Become part of this campaign to save Tampa Bay by giving your time. Many local agencies and conservation groups need your help to make a difference'. The videoaccompanying the display promotes regulation, conservation easements, the purchase of conservation lands, advocacy and engagement with politicians and conservation agencies.

Brooker Creek's exhibits wentfurther in pointing toward larger scale, less personal suggestions, including 'designing energy efficient homes', using semi-pervious pavers in parking lots, and reducing fertilizer use on golf courses.

Figure 17: Collaborative Management at Weedon Island

Redevelopment of downtown areas is suggested in lieu of suburban growth that results in sprawl and habitat loss. No suggestions are made concerning how citizens might encourage or support these types of planning decisions, however. 
Collectively, the preserves' exhibits focus strongly on human interactions with the environment, with many suggestions for personal behavioural change and, as such, encompass notions of active citizenship on behalf of the larger ecological community. Nonetheless, the exhibits' narratives do not challenge dominant tropes that emphasize individual rather than collective action and position citizens primarily as consumers operating in the private sphere.

Perhaps the most troubling silence is the complete absence of references to the potential impact of climate change on the region. Recent research by Janet Swim and colleagues (2017) found that while many zoos, natural history museums, and national preserves are working to bring climate change education into their exhibits, this is a difficult task, hampered by the political context and lack of support by individual institutions. Despite these recognized obstacles, incorporating climate change into permanent exhibits in Florida should be prioritized, as the state is often labelled as 'ground zero' for climate impacts in the United States.

\section{Discussion and Conclusion}

The collective narrative arising from the preserves' exhibits is one of human impact on nature. The preserves place significant emphasis on highlighting and exploring the human impact on local ecosystems, watersheds and wildlife. This is an encouraging finding and illustrates how preserve exhibits reflect the goals and values of EE, moving beyond merely providing scientific information about the local area to offering normative messages about human responsibility for the environment. Preserve exhibits engage all four foci of environmental education: information, participation, emotional engagement, and sustainable action; below, we summarize the overall fulfilment of these four expectations for environmental exhibits.

The first expectation, that nature preserves provide information and knowledge about local ecosystems and their inhabitants, is well satisfied at the preserves, as each exhibit conveys detailed information about local flora, fauna and ecosystems. Furthermore, all exhibits offer opportunities for visitors to participate through tactile, auditory and interactive activities, although engagement was often hampered by non-functional components. Signage that poses questions to the audience provides opportunities for visitors to co-construct the narrative of human-nature relationships in the region.

All exhibits suggest individual actions that visitors may take to help ameliorate local environmental challenges, using emotional engagement to increase visitor participation and connection to the artefacts on display. Sustainable action, however, should suggest both collective action and structural changes that visitors might engage in, encourage, and support in their communities. Moving beyond individual behaviour, the exhibits sporadically suggest larger scale, more complex activities. Because the exhibits tend to focus heavily on place defined as the specific ecosystems bounded by the preserve's borders - the larger preserves $(\mathrm{BC}$ and $\mathrm{WI}$ ) may have more opportunity to integrate largescale processes of development and human impact on landscapes than the smaller park $(\mathrm{BH})$. Overall, exhibits at all three preserves tend to perpetuate the notion of self-regulation and the 'disciplining' of individuals as the primary carriers of responsibility for environmental crisis and solutions.

\section{Imagining Environmental Citizens}

The environmental citizen imagined by the exhibits is of relatively high socioeconomic status, owning a home with a yard, a car and possibly a boat; this imagined audience falls within the modernist narrative of citizenship and emphasizes participants' roles as citizenconsumers. Because suggested actions target the personal behaviour of this demographic, critical opportunities to encourage other kinds of advocacy on behalf of nature are missed. It is worth considering how exhibits might address a broader citizenry and promote collective action to change large-scale destructive systems. For example, how might an apartmentdwelling, working class citizen visiting a preserve exhibit be engaged and moved toward sustainable action for the environment? Without a yard, or a house over which the person has control, issues of landscaping, water management, wildlife, and energy efficient design are meaningless. Some ideas emerge from BC's exhibit, which engages visitors in conversation about urban development, an important issue in the region. Leveraging this connection to encourage collective action through citizen engagement in the planning process, for example, is one possible strategy. 
Our analysis supports the notion that exhibits in nature preserves imagine visitors as middle-class, of relatively high socioeconomic status and probably white. Class is certainly a clear bias in the perspective of text in the displays. It may also be true that an emphasis on visitors' assumed desire to connect with wildlife inadvertently discourages people of colour from engaging with the exhibit (Finney 2014). Reconsidering how citizens are imagined in park exhibits might be one step toward creating a more welcoming and inclusive space.

\section{Imagining Ecological Community}

To what extent do preserve exhibits challenge the dominant ideology of human exceptionalism and separation from nature? Are humans construed as members of a broader ecological community? As Cameron noted in her work on the London Museum of Science, museum exhibits 'suggest that humans are there to protect Nature; are custodians of nature in a way that displays hubris and claims to patriarchal continuity; that museums as modernist institutions give themselves the authority to speak for the nonhuman' (Cameron 2015b: 51). Local park exhibits reflect this dominant societal narrative and position humans as caretakers and custodians of an objectified nature (live animal displays confirm this stewardship role). While humans are clearly present as members of the local ecology in the three park exhibits, the displays fall short of engaging with more complex notions of human entanglement with non-human nature. An emphasis on science, observation (of animal parts, for example) and management of the environment reproduce human dominion over nature. Indeed, the very character of parks - as places separate from the landscape where humans dwell - may present significant challenges for constructing narratives that articulate humans as a speciesamong-others, deeply embedded in a shared biocommunity, rather than separate from it.

\section{Suggestions for Enhancing Emotional Connections}

Boyd Hill has a unique opportunity to capitalize on its aviary display. The connection people tend to feel with live animals could be leveraged to encourage participation in planning to preserve open space and animal habitat, thereby discouraging development that puts other species at risk. Opportunities for emotional connection with animals, a powerful affective experience, are present at two of the three preserves through live animal exhibits, taxidermy displays, and other touch displays of animal remnants. The third preserve's animal representations are all manufactured and encased in polycarbonate, limiting visitor engagement. The loss of 'authenticity' of these objects may lessen their power as material representations of living beings (Appadurai 1986). WI might seek additional avenues for increasing the emotional engagement of its visitors through bodily encounters with live animals or their remnants.

Rhetorical analysis requires that we listen for the silences in the narrative. Missing from the narrative here are larger issues; for example, nowhere in the exhibits is climate change even referenced. This is a glaring omission, especially considering the already visible impact of sea level rise and large, powerful storms such as Hurricane Michael on the state. While the political context may make it difficult for public facilities to engage in conversations about climate change, bolder action to rectify this silence is needed.

The use of material artefacts to create narratives about the environment is an important and lasting feature of many nature preserves. As sites of public education about the environment, park displays can engage visitors in dialogue about citizen responsibility for nature. Key advancements in museum theory can be applied to these exhibits to enhance their effectiveness in engaging visitors, expanding and diversifying their representations of environmental citizenship, and encouraging personal and collective action on behalf of nature. Persistent tensions between cultural narratives of the individual and the collective, the personal and the structural, and between complacency and transformation, are reflected in park displays. The challenge for educators and curators is to balance these tensions, to craft opportunities for emotional engagement and participation in knowledge creation, thereby creating pathways toward meaningful action for diverse environmental citizens. Even harder to achieve, perhaps, is the goal of creating exhibit experiences that undermine traditional nature-human dualisms and ask visitors to see themselves as just one species in a community of living things. 


\section{Notes}

1 This topic is explored in Johns and Pontes (forthcoming).

2 Pinellas County, 2019. https://datausa.io/profile/geo/pinellas-county-fl\#demographics

3 Park Director, interview by R. Johns, November 2018, at Boyd Hill Nature Preserve, St Petersburg, Florida.

\section{References}

Appadurai, A. (1986) 'Introduction: Commodities and the Politics of Value', in Arjun Appadurai (ed) The Social Life of Things: Commodities in Cultural Perspective, 3-63, Cambridge: Cambridge University Press.

Arnold, K. (2006) Cabinets for the Curious: Looking Back at Early English Museums, Burlington, VT: Ashgate.

Ballantyne, R., Packer, J. and Falk, J. (2011) 'Visitors' Learning for Environmental Sustainability: Testing Short-and Long-Term Impacts of Wildlife Tourism Experiences Using Structural Equation Modeling', Tourism Management 32 (6) 1243-52.

Berkowitz, A., Ford, M. and Brewer, C. (2005) 'A Framework for Integrating Ecological Literacy, Civics Literacy, and Environmental Citizenship in Environmental Education', in Edward Johnson and Michael Mappin (eds) Environmental Education and Advocacy: Changing Perspectives of Ecology and Education, 227-66, Cambridge, MA: The MIT Press.

Bulbeck, C. (2005) Facing the Wild: Ecotourism, Conservation and Animal Encounters, New York NY: Earthscan.

Byrne, J. and Wolch, J. (2009) 'Nature, Race, and Parks: Past Research and Future Directions for Geographic Research', Progress in Human Geography, 33 (6) 74365.

Cameron, F. (2015a) 'Ecologizing Experimentations: A Method and Manifesto for Composing a Post-humanist Museum', in Fiona R. Cameron and Brett Neilson (eds) Climate Change and Museum Futures, 16-33, New York: Routledge.

(2015b) 'We Are on Nature's Side? Experimental Work in Re-writing Narratives of Climate Change for Museum Exhibitions', in Fiona R. Cameron and Brett Neilson (eds) Climate Change and Museum Futures, 51-77, New York: Routledge.

Cameron, F., Hodge, B. and Salazar, J. (2015) 'Conclusion: Climate Change Engagement: A Manifesto for Museums and Science Centers', in Fiona R. Cameron and Brett Neilson (eds) Climate Change and Museum Futures, 248-68, New York: Routledge.

Chakrabarty, D. (2002) 'Museums in Late Democracies', Humanities Research, IX (1) 5-12.

Corbett, J. (2018) Out of the Woods: Seeing Nature in the Everyday, Reno NV: University of Nevada Press.

Dawson E. (2013) 'Developing Inclusive Informal Science Education Practice: Useful Concepts From Research', Enterprising Science Research Briefs Series, Kings College: London. 
(2014) '“Not Designed for Us”: How Science Museums and Science Centers Socially Exclude Low-Income, Minority Ethnic Groups', Science Education, 98 (6) 981-1008.

DeWalt, K. and DeWalt, B. (2002) Participant Observation: A Guide for Fieldworkers, Lanham MD: AltaMira Press.

Falk, J., Koran, J. and Dierking, L. (1986) 'The Things of Science: Assessing the Learning Potential of Science Museums', Science Education, 70 (5) 503-8.

Finney, C. (2014) Black Faces, White Spaces: Reimagining the Relationship of African Americans to the Great Outdoors, Chapel Hill NC: The University of North Carolina Press.

Foss, S. (2009) Rhetorical Criticism: Exploration and Practice, $4^{\text {th }}$ edition, Long Grove IL: Waveland Press.

Hames, R. (2007). 'The Ecologically Noble Savage Debate,' Annual Review of Anthropology, 36, 177-90.

Jacobs, M. (2012) 'Human Emotions Toward Wildlife', Human Dimensions of Wildlife, 17 1-3.

Janes, R. (2007) 'Museums, Social Responsibility and the Future', in Simon J. Knell, Suzanne MacLeod and Sheila Watson (eds) Museum Revolutions: How Museums Change and are Changed, 160-72, London: Routledge.

Johns, R.A. and Pontes, R. (2019) 'Parks, Rhetoric and Environmental Education: Challenges and Opportunities for Enhancing Ecoliteracy', Journal of Outdoor and Environmental Education 22 (1) 1-19.

(forthcoming). 'Educating with Skins and Bones: Material representations of animals in permanent exhibits at local parks', Material Culture.

MacGregor, S. (2006) 'No Sustainability Without Justice: A Feminist Critique of Environmental Citizenship', in Andrew Dobson and Derek Bell (eds) Environmental Citizenship, 101-26, Cambridge, MA: The MIT Press.

Manubay, G., Smith, J., Houston, C., Schulz, K., Dotzour, A. and De Young, R. (2002) 'Evaluating Exhibits that Promote Conservation Behavior: Developing a Theoretical Framework', in Proceedings of the 31st Annual North American Association for Environmental Education Conference, 6-11 August, Ann Arbor MI: University of Michigan.

Mazur, N. (1998) 'Between the Turnstiles: Zoos as Agents of Environmental Education', Australian Journal of Environmental Education, 14 71-80.

Monroe, M., Andrews, E. and Biedenweg, K. (2008) 'A Framework for Environmental Education Strategies', Applied Environmental Education \& Communication, 6 (3-4) 205-16.

Mulcahy, D. and Witcomb, A. (2018) 'Affective Practices of Learning at the Museum: Children's Critical Encounters With the Past', in Laurajane Smith, Margaret Wetherell and Gary Campbell (eds) Emotion, Affective Practices and the Past in the Present, 213-29, London: Routledge.

Pedersen, H. (2002) 'Animals on Display: The Zoocurriculum of Museum Exhibits', Critical Education, 1 (8) 1-16. 
Poliquin, R. (2012) The Breathless Zoo: Taxidermy and the Cultures of Longing, University Park PA: Pennsylvania State University Press.

Salazar, J.F. (2011) 'The Mediations of Climate Change: Museums as Citizens' Media', Museum and Society 9 (2) 123-35.

Saldaña, J. (2015) The Coding Manual for Qualitative Researchers, London: Sage.

Schild, R. (2016) 'Environmental Citizenship: What Can Political Theory Contribute to Environmental Education Practice?', The Journal of Environmental Education, 47 (1) 19-34.

Swim, J., Geiger, N., Fraser, J. and Pletcher, N. (2017) 'Climate Change Education at

Nature-Based Museums', Curator: The Museum Journal, 60 (1) 101-19.

Szerszynki, B. (2006) 'Local Landscapes and Global Belonging: Toward a Situated Citizenship of the Environment', in Andrew Dobson and Derek Bell (eds) Environmental Citizenship, 75-100, Cambridge, MA: The MIT Press.

Taylor, G.D. (1989) 'The United States Pleasure Travel Market', Journal of Business Research, 18 (1) 1-79.

Witcomb, A. (2013) 'Understanding the Role of Affect in Producing a Critical Pedagogy for History Museums', Museum Management and Curatorship 28 (3) 255-71.

\section{Authors}

Rebecca A. Johns, Ph.D

Department of Society, Culture and Language

University of South Florida St. Petersburg

140 7th Ave S,

St. Petersburg, FL 33701

rjohns@mail.usf.edu

Rachelle J. Pontes, Graduate Student

Department of Florida Studies

University of South Florida St. Petersburg

140 7th Ave S,

St. Petersburg, FL 33701

pontesr@mail.usf.edu 